\title{
Control of Impingement Heat Transfer Using Mist ${ }^{*}$
}

\author{
Azusa KANAMORI**, Munehiko HIWADA ${ }^{* *}$, Junji MIMATSU**, \\ Hiraku SUGIMOTO $^{* *}$ and Kenyuu OYAKAWA ${ }^{* * *}$ \\ **Department of Mechanical and System Engineering, Gifu University, \\ 501-1193, 1-1, Yanagido, Gifu, Gifu, Japan \\ E-mail: hiwada@gifu-u.ac.jp \\ ***Department of Mechanical and System Engineering, University of the Ryukyus, \\ 903-0213, 1, Senbaru, Nishihara, Nakagami, Okinawa, Japan
}

\begin{abstract}
Impingement heat transfer from a circular orifice jet by using latent heat of water mists was studied experimentally. The amounts of mists of about Zauter's mean diameter $14 \mu \mathrm{m}$ were from 60 to $200 \mathrm{~g} / \mathrm{h}$ within a range where liquid films were not formed on the target plate and mists were added near the orifice edge. Experiments covered Reynolds numbers from 12,500 to 50,000 and a heat flux is $1,400 \mathrm{~W} / \mathrm{m}^{2}$. The experimental results indicate that adding mists had little influence on free jet mean velocity profiles and target plate pressure coefficients. On the other hand, mists had a strong influence on temperature and humidity profiles of a free jet and they also influenced Nusselt number distributions on the target plate. Increases of mists and Reynolds number caused increases in Nusselt number on the developed region. In addition, we investigated influence of the way mists were added and these results showed that Nusselt number was influenced not only by the amounts of mists but also by the adding method. Local Nusselt number profiles with mists were closely related to temperature distributions of the free jet at the location corresponding to the target plate.
\end{abstract}

Key words: Impingement Jet, Heat Transfer, Water Mist Cooling

\section{Introduction}

One of the most challenging energy problems is the effective use of energy in the improvement of heat exchanger efficiency, especially in the case of low quality energy. Impingement jet $^{(1-4)}$ has been used widely in industrial fields such as manufacturing processes of with glass or steel requiring cooling, heating and drying, because it provides a high heat transfer coefficient.

However, in general control of impingement heat transfer is very poor and only a few control methods, such as the changes in velocity profiles at the exit of a nozzle by using coaxial dual nozzles $\left(\right.$ Shakouchi ${ }^{(5)}$ ), a non-circular nozzle and a three-dimensional nozzle $\left(\right.$ Colucci $^{(6)}$, Oyakawa $\left.{ }^{(7)}\right)$ have been reported.

Recently, the cooling method using vapor latent heat of small amounts of water mist has been considered as an active heat transfer control method. Graham ${ }^{(8)}$ studied water or methanol/air mist jet impingement cooling using a coaxial jet atomizer under the condition that surface-averaged heat fluxes could be dissipated with the mist. Wang ${ }^{(9)}$ investigated the mist/steam heat transfer of three rows of circular jet impingement in confined channel. The $\mathrm{mist} / \mathrm{steam}$ flow was mixed before jets. 
In this study, the work-saving cooling mechanism and the possibility of a heat transfer enhancement from a circular orifice jet with water mists which were added near the orifice edge have been studied experimentally.

\section{Nomenclature}

$A$ : area of the orifice

$C_{p}:$ wall pressure coefficient

$c:$ specific heat

$d:$ diameter of the orifice

$L:$ distance between orifice and target plate

$m$ : weight flow rate of the jet

$N u$ : local Nusselt number on the target plate

$N u_{c}$ : conversion Nusselt number (defined by Eq. (5))

$N u_{d}$ : normalized maximum Nusselt number with mists (defined by Eq. (3))

$N u_{\max }$ : maximum Nusselt number with mists

$N u_{n}$ : maximum Nusselt number without mist

$\overline{N u}$ : averaged Nusselt number on the target plate (defined by Eq. (4))

$p:$ static pressure

$Q$ : latent heat

$Q_{m}:$ the amount of added mists

$q$ : heat flux

$R e:$ Reynolds number $=U_{0} d / v_{\text {air }}$

$R_{h}$ : relative humidity

$r$ : radical coordinate on the target plate

$T:$ temperature

$U$ : velocity of the jet

$x$ : coordinate along the jet central

$y, z:$ coordinate along the target plate (see Fig. 2)

$\lambda:$ thermal conductivity

$v:$ kinematics viscosity

$\rho:$ density

\section{Subscript \\ air : dry air \\ $w:$ target plate \\ 0 : orifice exit}

\section{Experimental Apparatus and Method}

Figure 1 shows the experimental apparatus and Fig. 2 shows the coordinate systems and symbols used in this report. An orifice is made in a brass plate $2 \mathrm{~mm}$ in thickness and 51 $\mathrm{mm}$ in diameter, $d$. Experimental Reynolds numbers, $R e$, are $(5.0,2.5,1.25) \times 10^{4}$ using a characteristic length, $d$, and characteristic velocity at the orifice exit, $U_{0}$ measured with an I-type hot wire anemometer.

In free jet experiments, temperature was measured with a sheath K-type thermocouple and humidity was measured with a capacity type polymer hygrometer.

In impingement experiments, heat transfer was conducted under a constant heat flux, $q_{w}$ of $1,400 \mathrm{~W} / \mathrm{m}^{2}$ using direct current to a thin stainless foil of $20 \mu \mathrm{m}$ thickness on a target plate. A local Nusselt number on the target plate was defined;

$$
N u=\frac{q_{w} \times d}{\lambda_{\text {air }}\left(T_{w}-T_{0}\right)}
$$


where $\lambda_{\text {air }}[\mathrm{W} / \mathrm{mK}]$ is the heat conductivity of dry air, $T_{0}$ is the temperature of the air jet at the orifice edge and $T_{w}$ is the temperature on the target plate. $T_{w}$ was measured with $\mathrm{Cu}-\mathrm{Co}$ thermocouples soldered on the back of the stainless foil. Static pressures on the target plate, $p_{w}\left[\mathrm{~kg} / \mathrm{m}^{2}\right]$, were measured using immersed bell type precision manometers and wall pressure coefficients on the target plate, $C_{p w}$, defined as;

$$
C_{p w}=\frac{2 p_{w}}{\rho_{\text {air }} \times U_{0}^{2}}
$$

where $\rho_{\text {air }}\left[\mathrm{kg} / \mathrm{m}^{3}\right]$ is the density of dry air.

As shown in Fig. 2, water mists were generated by an ultra-sound wave type humidifier, and they were added at the ambient temperature to the jet from the $z$-axis side near the orifice edge. Zauter's mean diameter ZMD was about $14 \mu \mathrm{m}$. The amounts of added mists, $Q_{m}$, were 60,120 , and $200 \mathrm{~g} / \mathrm{h}$, a region where liquid films were not formed on the target plate. In $R e=5.0 \times 10^{4}$, the amounts of mists were converted to mist densities [ppm], that is the ratio of water mist mass flow rate to air mass flow rate are as follows; $60 \mathrm{~g} / \mathrm{h}$ to 415 ppm, $120 \mathrm{~g} / \mathrm{h}$ to $831 \mathrm{ppm}$ and $200 \mathrm{~g} / \mathrm{h}$ to $1380 \mathrm{ppm}$.

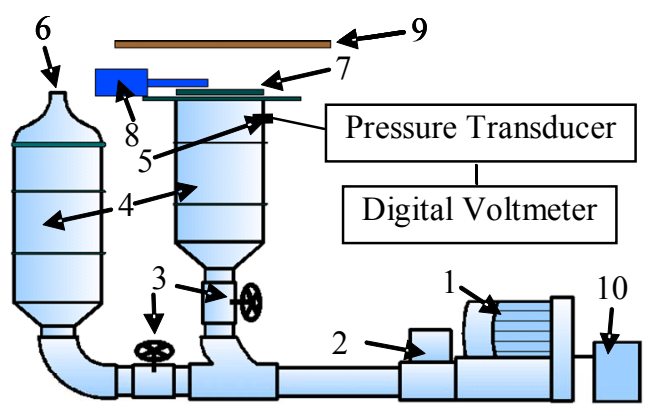

1. Blower, 2. Admission port, 3. Valve,

4. Rectify section, 5 . Static pressure hole,

6. Nozzle, 7. Orifice, 8 . Humidifier,

9. Impinging plate, 10 . Inverter

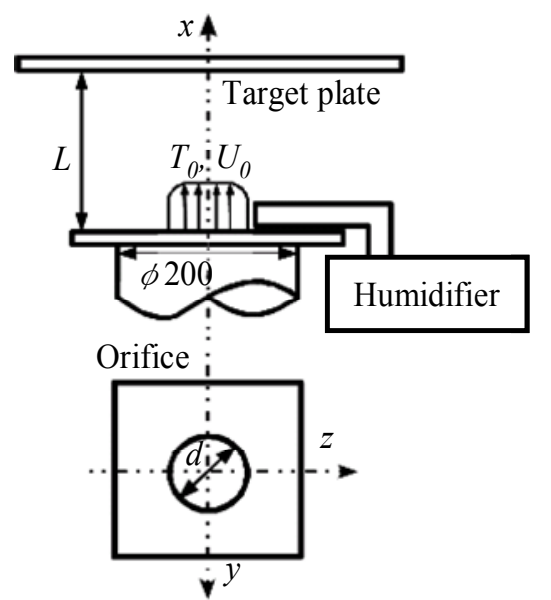

Fig. 2 coordinate systems and main symbols

Fig. 1 Experimental apparatus

\section{Experimental Results and Considerations}

\subsection{Free Jet}

Figure 3 shows mean velocities, $U / U_{0}$, in the streamwise direction of the free jet at special sections, $x / d$, are 8,12 and 16. $Q_{m}$, are zero and $200 \mathrm{~g} / \mathrm{h}$ for a constant $R e=5.0 \times$ $10^{4}$. Both results show nearly the same profile indicating that mists did not have a significant influence on the free jet velocity distribution.

Figure 4 shows the local temperature, $T[\mathrm{~K}]$ and profiles of the free jet with mists in the $y$ direction. $R e$ and $x / d$ are the same as those given in Fig. 3. $Q_{m}$ are $0,60,120$ and $200 \mathrm{~g} / \mathrm{h}$. Compared with profiles without mist, temperatures near the axis center of the free jet were the lowest when mists were added. Moreover, an increase of $Q_{m}$ brought a drop in temperatures in the free jet. On the downstream side, the variations of temperatures were smaller and the influences of mists were not as large.

Figure 5 shows the local relative humidity, $R_{h}[\%]$, distributions in the $y$ direction of the free jet with the added mists. $Q_{m}, R e$ and $x / d$ are the same as those given in Fig. 4. $R_{h}$ near the axis center of the free jet with mists was higher than without mist. Moreover, as larger mists were added, the jet became more humid. At the downstream side, the influence of mists was weak.

As mentioned previously the addition of mists to the free jet in this experimental ZMD hardly influenced its mean velocity profiles. On the other hand, mists had a strong influence on temperature and humidity profiles in the free jet. 


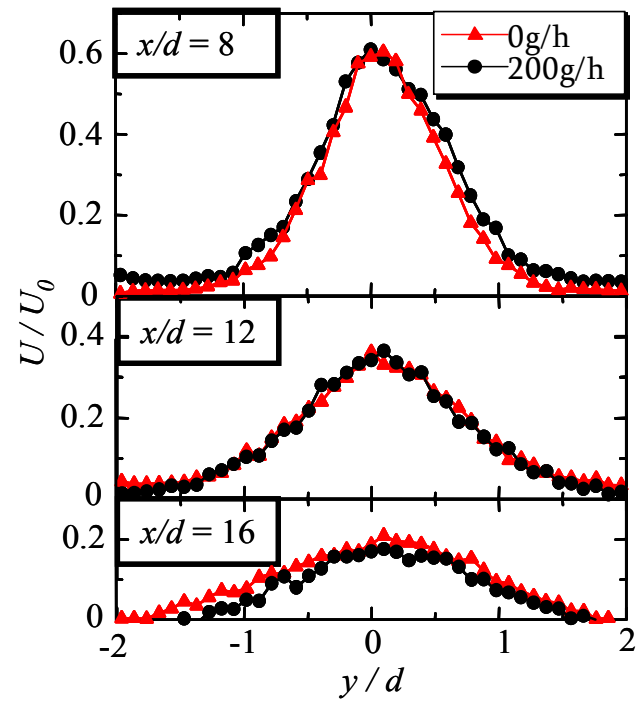

Fig. 3 Influence of mists on mean velocity profiles $\left(R e=5.0 \times 10^{4}\right)$

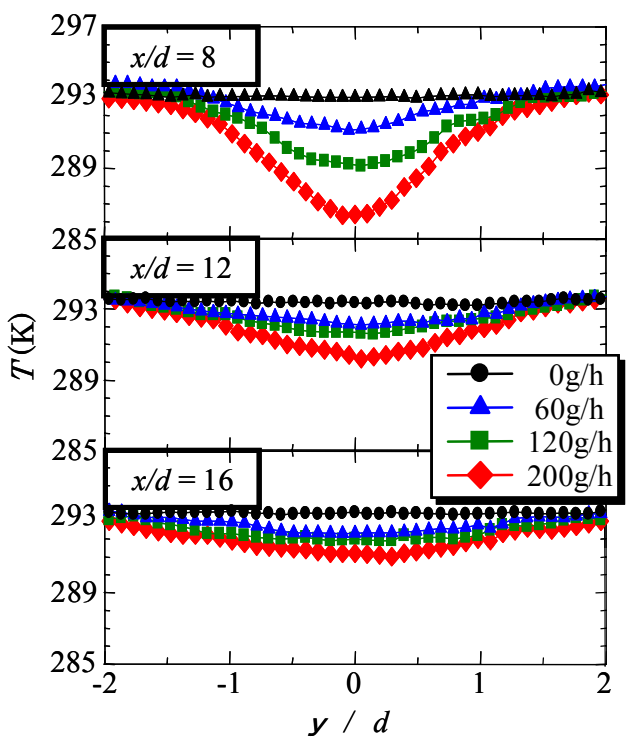

Fig. 4 Influence of mists on local temperature profiles $\left(R e=5.0 \times 10^{4}\right)$

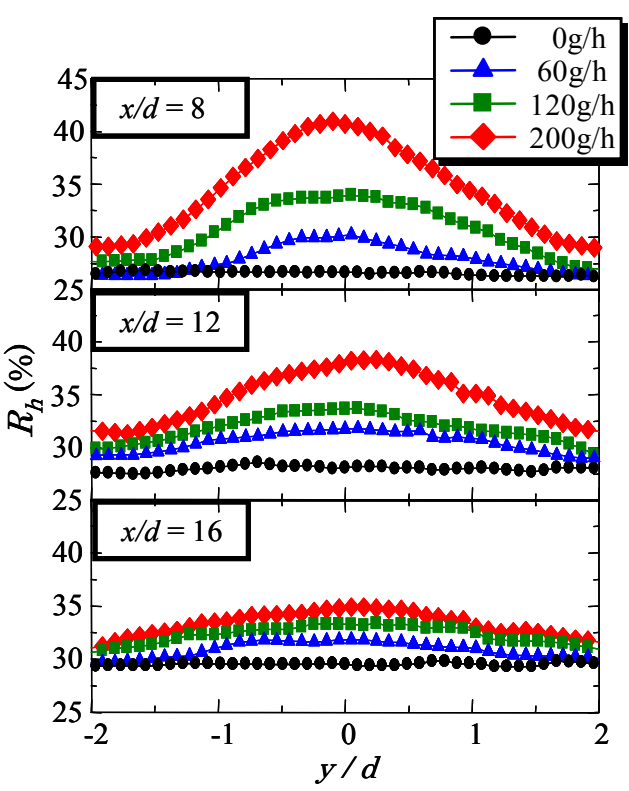

Fig. 5 Influence of mists on local relative humidity profiles $\left(R e=5.0 \times 10^{4}\right)$

\subsection{Impingement Jet}

\subsubsection{Pressure coefficient profile}

Figure 6 shows $C_{p w}$ profiles in $y$ and $z$ directions. Orifice-to-target plate spacing, $L / d$, is $2,4,8,12$ and 16 and a constant $R e$ is $5.0 \times 10^{4} . Q_{m}$ are zero and $200 \mathrm{~g} / \mathrm{h}$. Both $Q_{m}$, profiles showed the same trend indicating that the amounts of mists in this experimental range did not affect the velocity distributions of an impinging jet region. Each profile of $y$ / $d$ and $z / d$ did not have an apparent difference. These results show that the direction of added mists has little influence on the pressure distributions.

\subsubsection{Local Nusselt number profile}

Figures 7(a) to (c) show $N u$ profiles on the target plate in $y$ and $z$ directions. $L / d$, are 8, 12 and 16 and $R e$ are $(5.0,2.5,1.25) \times 10^{4} . Q_{m}$, are $0,60,120$ and $200 \mathrm{~g} / \mathrm{h}$. Compared with the profiles without mist, for $L / d=8$ and $R e=5.0 \times 10^{4}$, the variations of $N u$ near the 


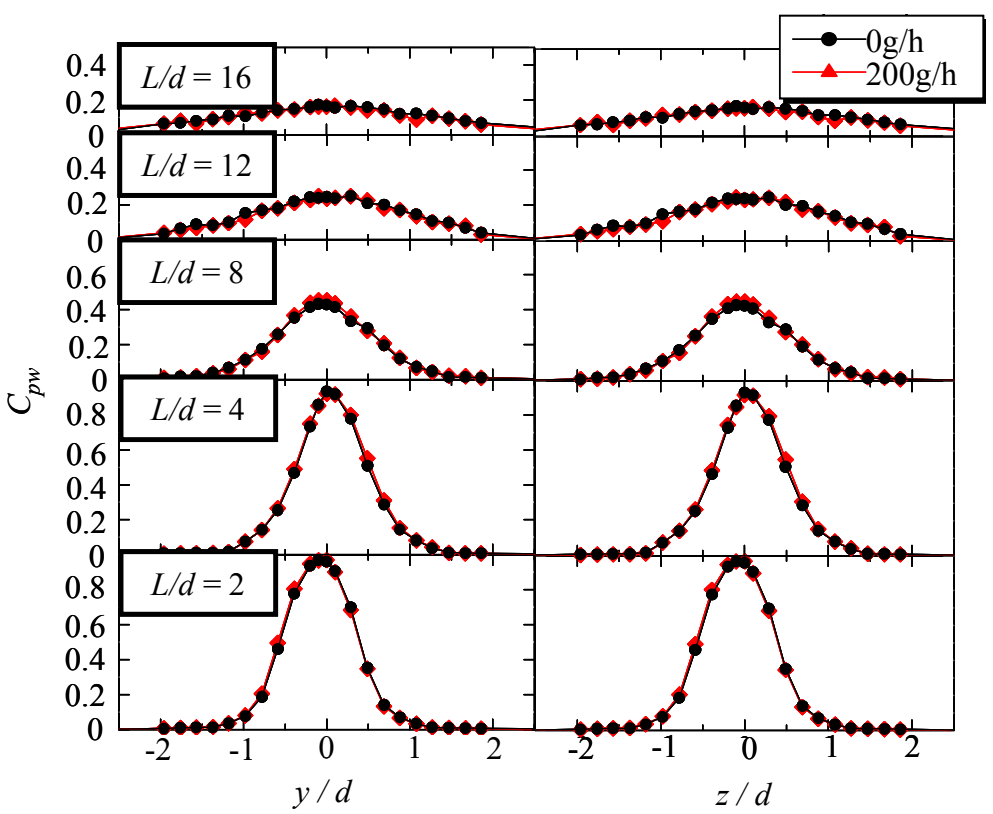

Fig. 6 Influence of mists on local wall pressure coefficients profiles $\left(R e=5.0 \times 10^{4}\right)$

center axis of the free jet are the largest for the maximum amount of added mists. However, in $|y / d|>1$ and $|z / d|>1, Q_{m}$ had only small differences in $N u$ distributions. The influence of added mists on $N u$ decreases as $Q_{m}$ decreases. In the downstream, the variations of $N u$ with $Q_{m}$ are small. When $R e$ are $(2.5$ and 1.25$) \times 10^{4}$, the lower Re produces small influences of mists on $N u$. The result that $N u$ profiles of $y / d$ are the same as those of $z / d$ shows that the influence of the direction of added mists on $\mathrm{Nu}$ profiles was small.

\subsubsection{Iso-Nusselt contour maps}

To recognize the influence of mists on plane variations of $N u$ on the target plate, Figs. 8 (a) and (b) show iso- $N u$ contour maps for $L / d=8$ and 16 and $R e=(5.0,1.25) \times 10^{4}$, respectively. The upper and lower parts of these figures show results without mist and with mist of $Q_{m}=200 \mathrm{~g} / \mathrm{h}$, respectively. An iso- $N u$ contour line with mists is wider than that without mist for both $L / d$. And the iso- $N u$ contour area increased when $L / d$ decreased or Re increased.

\subsubsection{Consideration of maximum Nusselt number}

In Fig. 7, $N u$ near the axial center, which is a maximum $N u$ in each cross section, increases with the increases in $Q_{m}$ and $R e$. Therefore, Fig. 9 shows relations between a normalized maximum $N u$ with mists, $N u_{d}$, and $R e . N u_{d}$ is defined as follows;

$$
N u_{d}=\frac{N u_{\max }-N u_{n}}{N u_{n}}
$$

where $N u_{n}$ is the maximum $N u$ without mist and $N u_{\max }$ is the maximum with mists. $Q_{m}$ are 60,120 and $200 \mathrm{~g} / \mathrm{h}$. In the cases of $L / d=16$ and 12 and $R e=1.25 \times 10^{4}, N u_{d}$ remained unchanged regardless of $Q_{m}$ or $R e$. In the case of $L / d=8$, the increases of $Q_{m}$ and $R e$ brought on increases in $N u_{d}$. For $R e=5.0 \times 10^{4}$ and $L / d=8$ and $Q_{m}=200 \mathrm{~g} / \mathrm{h}, N u_{d}$ had the largest value.

Figure 10 shows relations between $N u_{\max }$ and $Q_{m}$ which were indicated as mist densities for $\operatorname{Re}=5.0 \times 10^{4}$ and $L / d=8$. A dramatically increased $N u_{\max }$ was observed near the border of $1000 \mathrm{ppm}$, that is, $Q_{m}=145 \mathrm{~g} / \mathrm{h}$. 


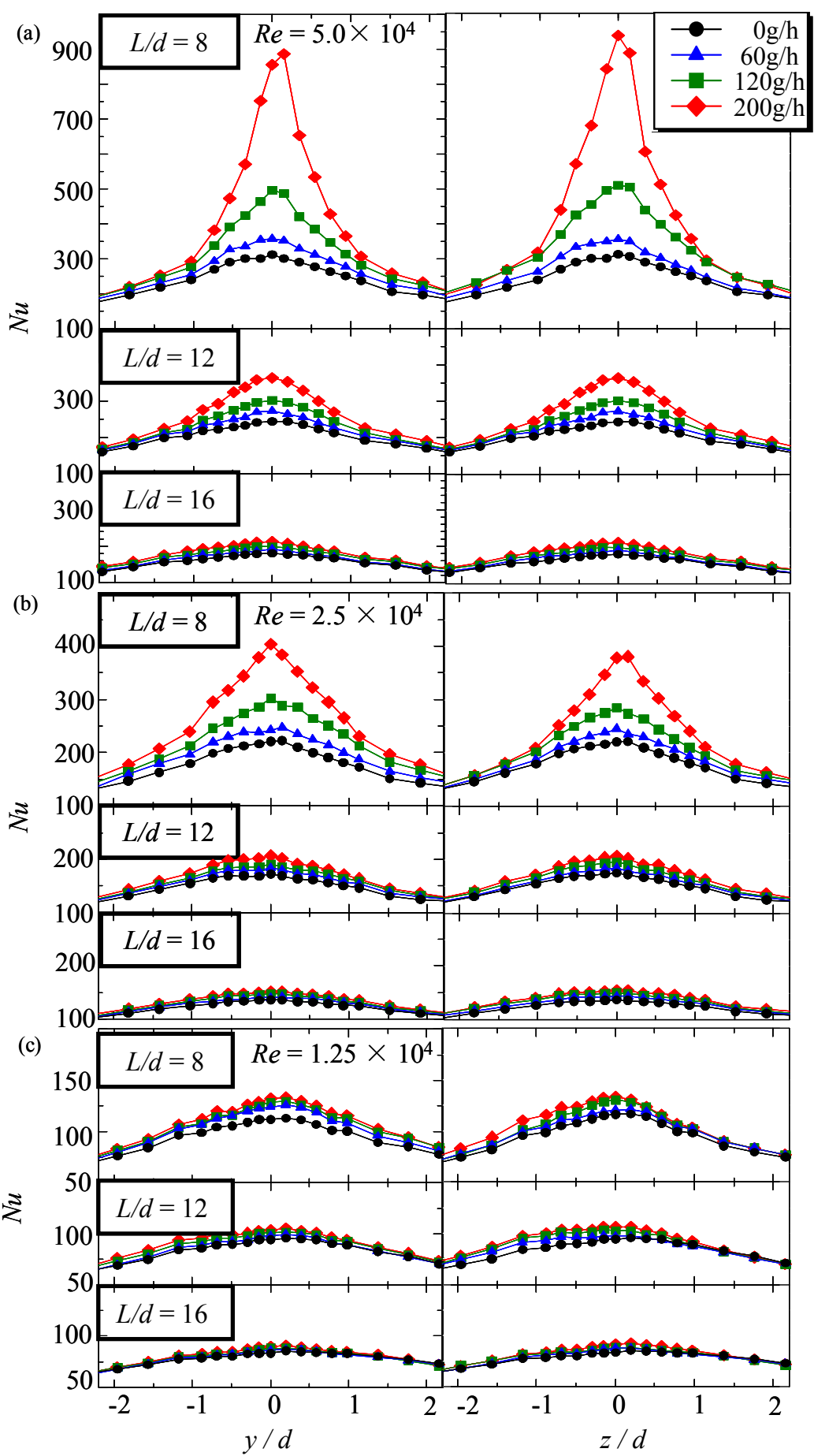

Fig. 7 Influence of mists on local Nusselt number profiles (a) $R e=5.0 \times 10^{4}$, (b) $R e=2.5 \times 10^{4}$, (c) $R e=1.25 \times 10^{4}$

\subsubsection{Consideration of averaged Nusselt number on the target plate}

Figure 11 shows the averaged $N u$ on the plate, $\overline{N u}$, in order to estimate the improvement of heat transfer on the impingement jet with mists. $\overline{N u}$ was defined as follows;

$$
\overline{N u}=\frac{1}{4 \pi d^{2}} \int_{0}^{2 d} 2 \pi r N u(r) d r
$$




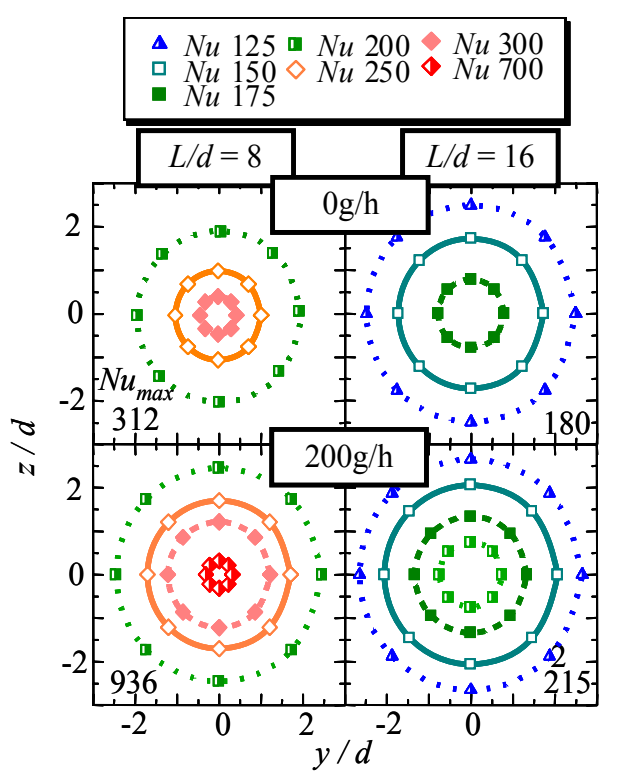

(a) $\operatorname{Re}=5.0 \times 10^{4}$

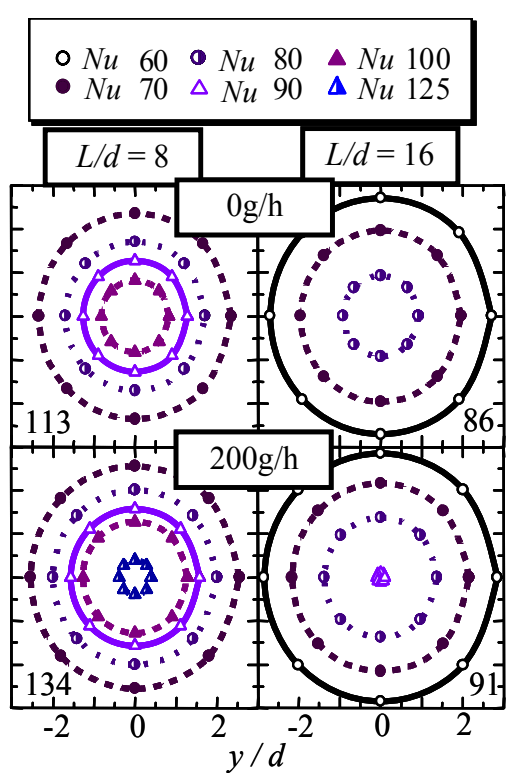

(b) $R e=1.25 \times 10^{4}$

Fig. 8 Iso-Nusselt number contour maps

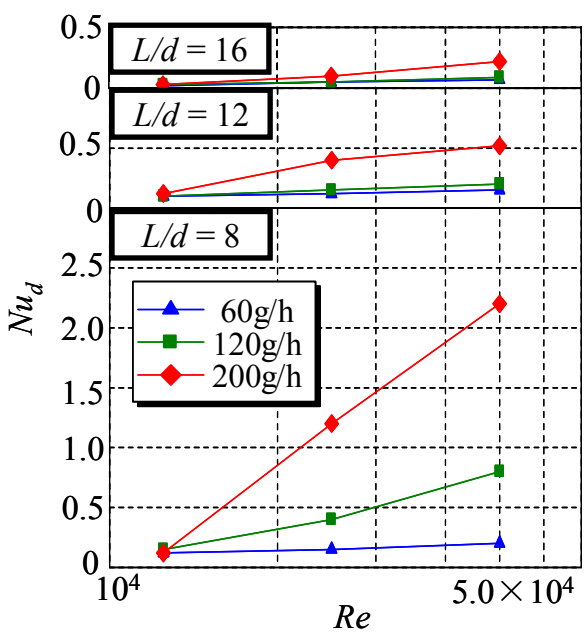

Fig. 9 Relation between normalized maximum Nusselt and Reynolds numbers

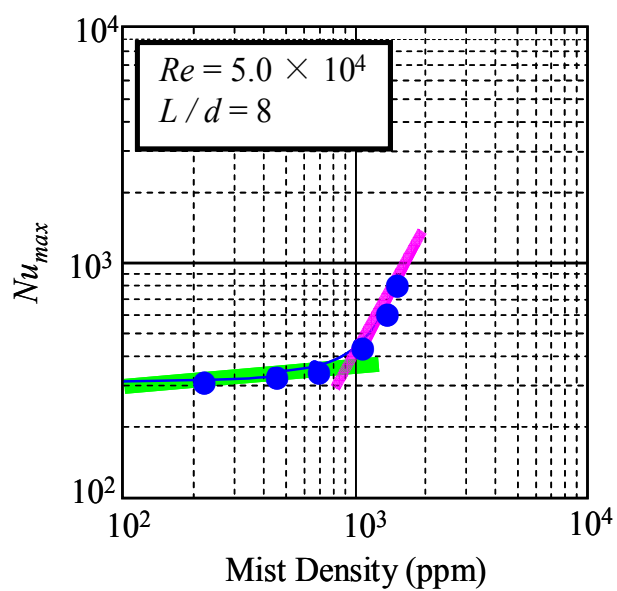

Fig. 10 Relation between maximum Nusselt number and mist density

where $N u(r)$ was determined from the $N u$ profile in Fig. 7 and where $r$ is the radial distance from the orifice center. For all $L / d$, when Re increased $\overline{N u}$ increased. Especially for $L / d$ $=8, \overline{N u}$ increased dramatically in the case of $Q_{m}=200 \mathrm{~g} / \mathrm{h}$.

Here, the result and consideration of $\S \S 3.1$ and 3.2 are summarized. First, as shown in Fig. 6, the pressure distribution did not change with mists addition. Therefore, the kinetic energy of the jet did not change with mists so that it was supposed from the free jet velocity distribution in Fig. 3. From this result, we considered that thermal energy change of the jet by latent heat of mists was one of the causes of the increasing of $N u$ with mists as shown in Fig. 7.

Next, compared with the result in Figs. 9 and 11, in the case of $R e=5.0 \times 10^{4}$ and $Q_{m}=$ $200 \mathrm{~g} / \mathrm{h}$, the $N u_{\max }$ was 2.2 times and $\overline{N u}$ was 1.8 times as much as without mist. It was suggested that the added mists did not influence on the whole jet but had a strong influence on near the axis center of the jet. In this result, it might be relevant to the followings, the temperature and humid distributions with mists in the cross section of the free jet stream 
direction were not uniform and then the decreasing of temperature near the axis center of the free jet with mists was large.

Moreover, as shown in Figs. 9 and 11, $N u$ increased with increasing $Q_{m}$, increasing $R e$ and decreasing $L / d$. We suggested that it was because the increasing of $Q_{m}$ brought the increasing of latent heat and the increasing of Re brought the increasing of mass flow rate, that is, the flow with decreased temperature by latent heat of mists and included mists reached downstream.

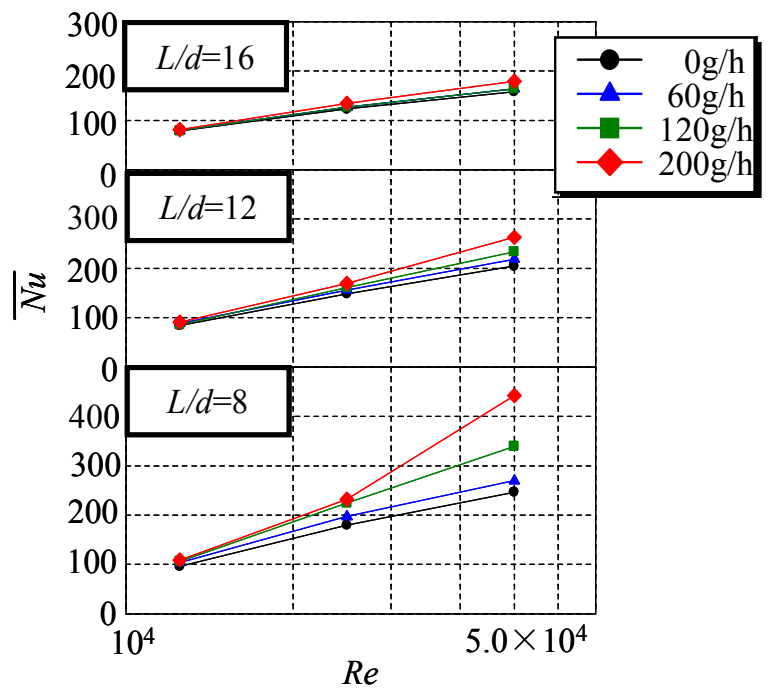

Fig. 11 Relation between averaged Nusselt and Reynolds number

\subsection{Evaluation of the added mist}

As mentioned in $\$ 3.1$, added mists in the free jet hardly influenced its mean velocity profiles. On the other hand, the mists had strong influence on temperature and humidity profiles in the free jet. Considering these points, two types of conversion were tried. A conversion temperature was $T_{c}$ was calculated by (1) the vapor latent heat of added mists and (2) the local temperature distribution in the free jet at the location corresponding to the target plate. Moreover a conversion $\mathrm{Nu}, \mathrm{Nu}$ was defined as follows;

$$
N u_{c}=\frac{q_{w} \times d}{\lambda_{\text {air }}\left(T_{w}-T_{0}-T_{c}\right)}
$$

\subsubsection{Evaluation by vapor latent heat}

We supposed that mists added to the jet vaporized perfectly. The temperature of the jet decreased uniformly by the latent heat, $Q[\mathrm{~kJ} / \mathrm{s}]$, and converted to a conversion temperature, $T_{c}$.

$$
Q=c_{\text {air }} m_{\text {air }} T_{c}
$$

where $c_{\text {air }}[\mathrm{kJ} /(\mathrm{kgK})]$ is the specific heat of dry air, and $m_{\text {air }}[\mathrm{kg} / \mathrm{s}]$ was the weight flow rate of the dry air jet showed by the following equation;

$$
m_{\text {air }}=\rho_{\text {air }} A_{0} U_{0}
$$

where $A_{0}$ is the area of the orifice. It is assumed that temperature equilibriums in the entrained ambient air are neglected and mists did not influence the jet flow behavior.

Figures 12(a) and (b) show the evaluated results of $N u$ in the cases of $L / d=8$ and 16, and $R e=5.0 \times 10^{4}$. Dark and open symbols are $N u$ and $N u_{c}$, respectively. In the case of $L / d$ $=8$, compared with $N u$ without mist, $N u_{c}$ increased a little near the center of the jet and decreased in the far center area. In the case of $L / d=16$, the converted value is smaller than that without mist. Moreover, in all $y / d$ this conversion was lower than without mist and this value was an over estimation. 


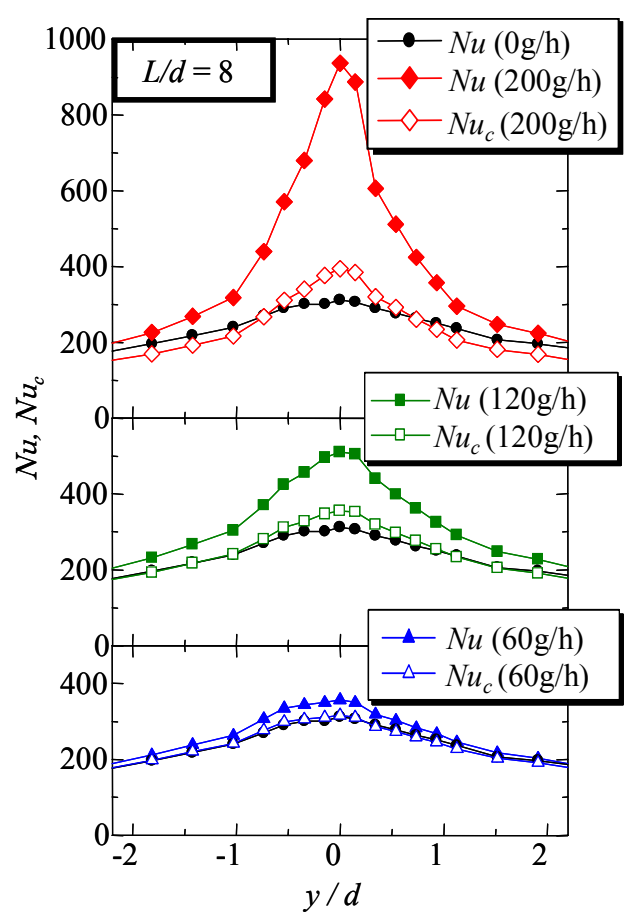

(a) $L / d=8$

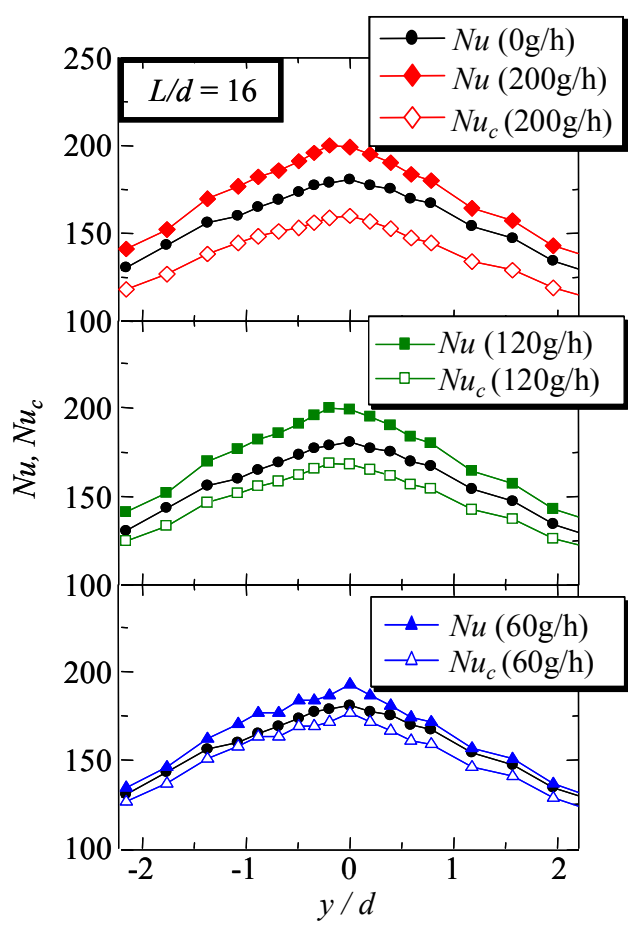

(b) $L / d=16$

Fig. 12 Conversed Nusselt number by latent heat $\left(R e=5.0 \times 10^{4}\right)$

\subsubsection{Evaluation by temperature distribution in a free jet at the location corresponding} to the target plate

The effect of added mists on the temperature distribution in the free jet did not have the uniformity shown in Fig. 4. The former estimation in \$3.3.1 did not take account of these facts. Then, added mists gave local temperature decreases as a result of vaporizing mists and its mixing with the surrounding fluid. In this section, it is supposed that a jet flow with the non-uniform temperature profiles at the location of the target plate in the free jet directly impinged on the target plate as an oncoming flow. Namely, a modified temperature $T_{c}(r)$ is;

$$
T_{c}(r)=T(r)-T_{0}
$$

where $T(r)$ is the local temperature in the free jet at the location corresponding to the target plate.

Figures 13(a) and (b) show the evaluated results in $R e=5.0 \times 10^{4}$ for $L / d=8$ and 16, respectively. In the case of $L / d=8$, converted $N u$ profiles agreed with $N u$ profiles without mist very close to the center of the jet. In the case of $L / d=16$, the converted values are large in all areas and this value was a little under estimation.

Compared with the former estimation based on latent heat, in \$3.3.1, this estimation is in good agreement with the result without mist. From these estimations, we presumed that $N u$ distributions with mists were closely related to temperature distributions in the free jet at the location corresponding to the target plate.

\subsection{Difference in the Addition Method of Mists}

\subsubsection{Free jet}

We also studied the influence of the way mists were added in order to confirm our conclusions in \$3.3.2. Figure 14 shows the mechanics of adding mists at the same $Q_{m}$. $Q_{m}$ was a constant $240 \mathrm{~g} / \mathrm{h}$ in all cases and the mists were added from (a)one pipe, (b)two pipes and (c)three pipes. In the above three cases for $R e=5.0 \times 10^{4}$ and $x / d=8$, Figs. 15(a) and (b) show temperature and humidity profiles, respectively. 


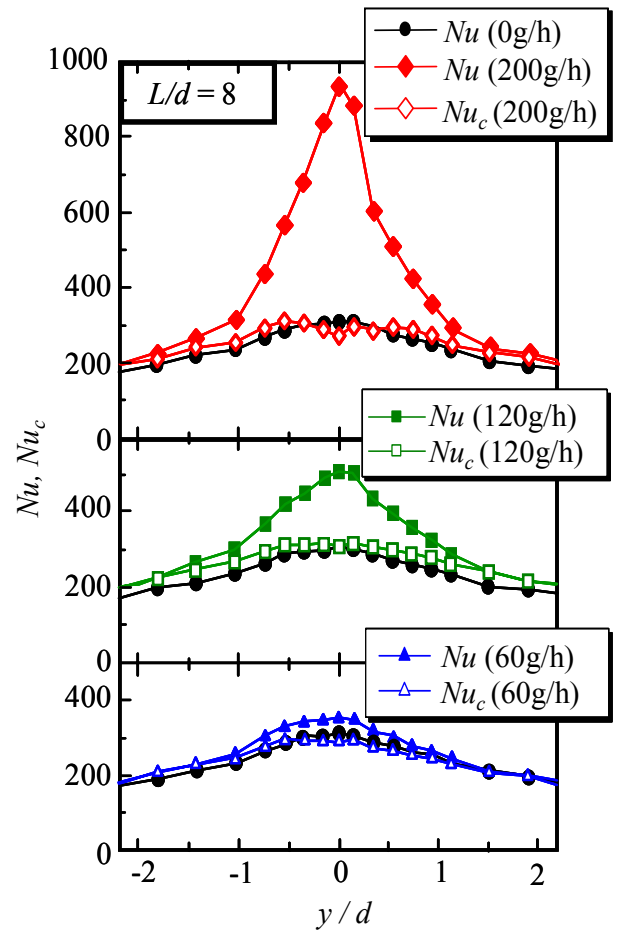

(a) $L / d=8$

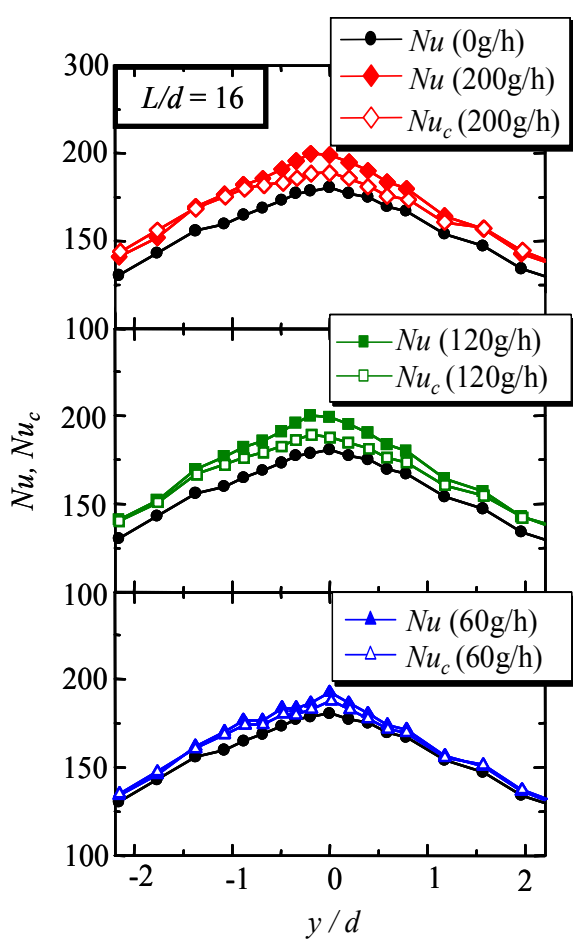

(b) $L / d=16$

Fig. 13 Conversed Nusselt number by local temperature distribution in free jet $\left(R e=5.0 \times 10^{4}\right)$

When mists were added from one pipe, differences between the free jet and ambient temperatures were the largest both at the $y$ - and $z$-axes. Moreover increases in the number of pipes produced a decrease in the temperature differences between jet and ambient ones. Humidity distributions showed the same trend. We assume that increasing the number of pipes reduced the density of mists at an added location and that the mists evaporated easily and diffused towards the upstream side.

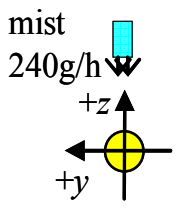

(a) one pipe

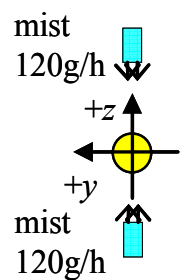

(b) two pipes

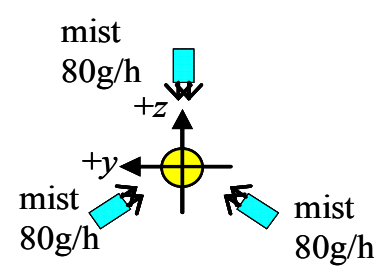

(c) three pipes

Fig. 14 The mechanics of adding mists

\subsubsection{Impingement jet}

Figure 16 shows $N u$ profiles of impingement jets in the case of $L / d=8$ with the same conditions of $Q_{m}$ and $R e$ as those in Fig. 15. Nu was greatest with mists added from one pipe while the temperature distribution of the free jet on the cross section was the smallest as shown in Fig. 15(a). From these results, the effects of mixture diffusions by added mists appear to be related to temperature distributions in the free jet. Figure 17 shows the results estimated by the same method as in \$3.3.2. These results show a fairly good estimation of the effect of additional mists in all cases accounting for the accuracy of the local temperature measurement in the free jet. 

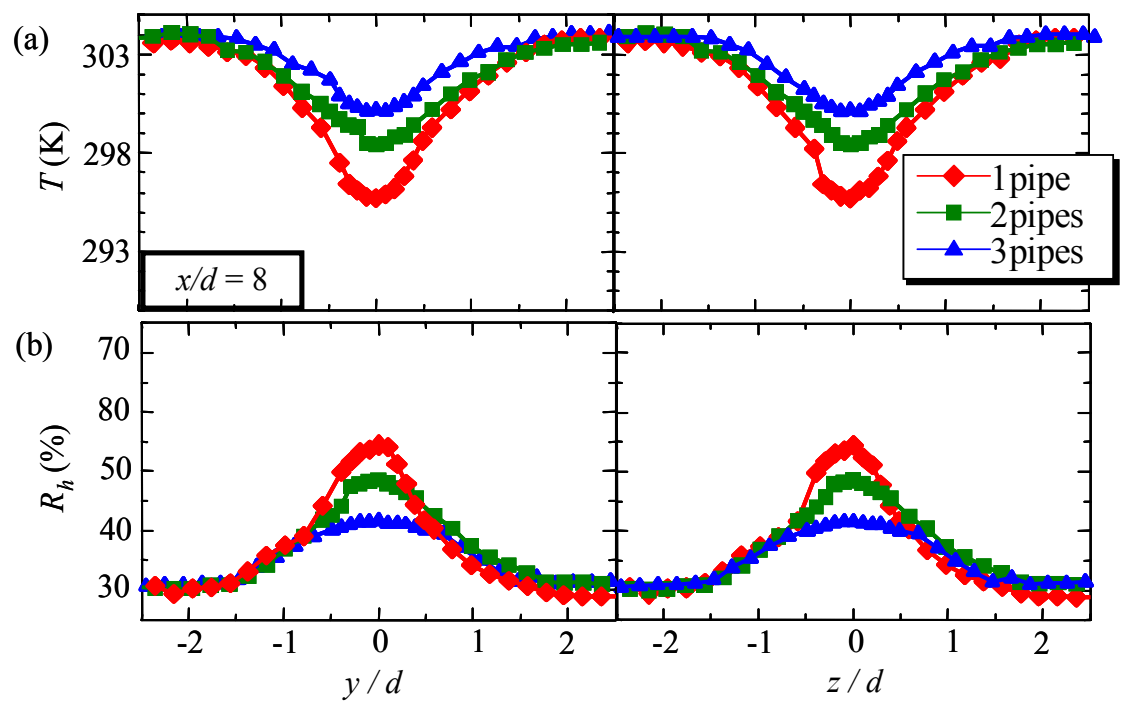

Fig. 15 Profiles with same amount of mists $240 \mathrm{~g} / \mathrm{h}\left(R e=5.0 \times 10^{4}\right)$

(a) Local temperature, (b) Local relative humidity

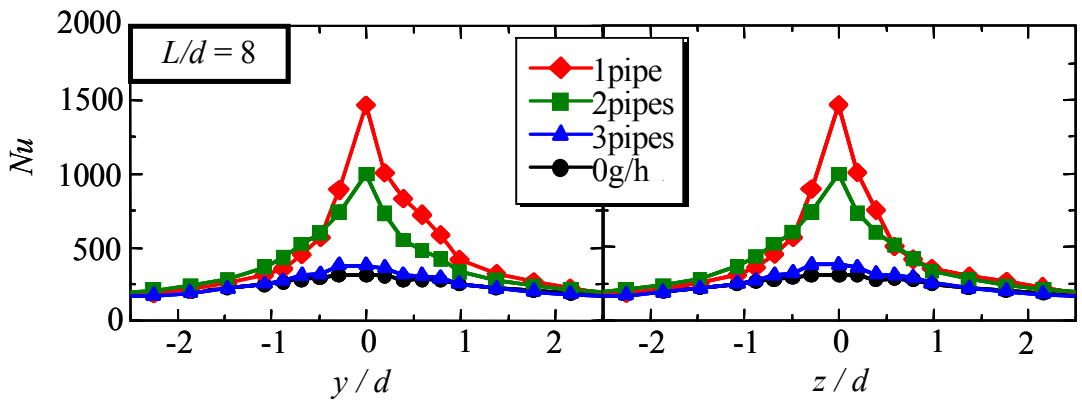

Fig. 16 Local Nusselt number profiles with same amount of mists $240 \mathrm{~g} / \mathrm{h}\left(\operatorname{Re}=5.0 \times 10^{4}\right)$

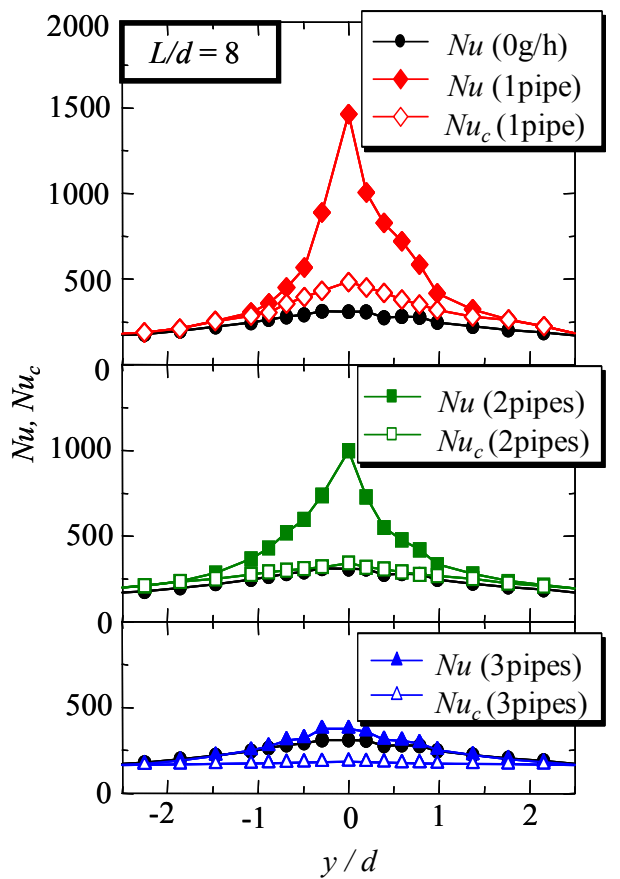

Fig. 17 Conversed Nusselt number by local temperature distribution in free jet $\left(R e=5.0 \times 10^{4}\right)$ 
However, several factors which contributed to evaporation such as a mist particle diameter or an ambient temperature and humidity might have great influence on the heat transfer. For example, it is considered that the evaporation time of mists becomes shorter when the mists particle diameter is smaller. Therefore, the mists diameter and distribution depend heavily on the temperature of the free jet. Moreover, in the case of the ambient temperature and humidity near saturation, it is suggested that the liquid film is formed on the target plate for large $L / d$.

\section{Conclusion}

When mists about Zauter's mean diameter $14 \mu \mathrm{m}$ were added to the jet from near the orifice edge within a range where liquid films were not formed on the target plate for $L / d$ $=8$ to 16 and $R e=(5.0,2.5,1.25) \times 10^{4}$, the following conclusions were obtained;

- Added mists did not influence the free jet mean velocity profiles and the target plate pressure coefficients.

- Added mists varied the local temperature and humidity distributions in the free jet and these distributions were not uniform, and $N u$ distribution on the target plate.

- In the same method of mists addition, $N u$ increased with increasing the mist amounts, increasing $R e$ and decreasing $L / d$.

- The mechanism of adding mists at the same amounts of mists brought the difference of temperature and humidity distributions in the free jet and $N u$ distribution on the target plate.

\section{Acknowledgement}

This work was partly supported by ONDA MFG. CO., LTD.

\section{References}

(1) Shakouchi, T., Jet Flow Engineering, (2004), Morikita Publishing Co., Ltd.

(2) G. N. Abramovich, The Theory of Turbulent Jets, (1963), The M. I. T. Press

(3) N. Rajaratnum, Turbulent Jets, (1976), Elsevier Scientific Publishing Company

(4) P. M. Sforza, et al., Studies on Three-Dimensional Viscous Jets, AIAA J., Vol. 4, No. 5 (1996), pp. 800-806.

(5) Shakouchi, T., et al., Flow Characteristics and Control of Turbulent Annular Jet (Effect of Coaxial Round Jet), JSME (Ser. B) (in Japanese), Vol. 63, No. 614 (1997), pp. 3278-3286.

(6) Colucci, D. W. and Viskanta, T., Effect of Nozzle Geometry on Local Convective Heat Transfer to a Confined Impinging Air Jet, Experimental Thermal and Fluid Science, Vol. 13 (1996), pp. 71-80.

(7) Oyakawa, K., et al., Effects of Nozzle Configuration on Impingement Heat Transfer, Proc. of ASME / JSME Thermal Eng. Conf., Vol. 1 (1995), pp. 377-383.

(8) K. M. Graham and S. Ramadhyani, Experimental and Theoretical Studies of Mist Jet Impingement Cooling, Journal of Heat Transfer, Vol. 118 (1996), pp. 343-349.

(9) T. Wang, et al., Mist/steam Heat Transfer of Multiple Rows of Impinging Jets, Int. J. of Heat and Mass Transfer, Vol. 48 (2005), pp. 5179-5191. 